\title{
Design and Simulation of Solar Monitoring Tracking System
}

\author{
Omorogiuwa Eseosa ${ }^{1,}$ Uhunmwangho Roland ${ }^{2}$ \\ Electrical/Electronic Engineering, Faculty of Engineering University of Port Harcourt, Rivers State \\ Electrical/Electronic Engineering, Faculty of Engineering University of Port Harcourt, Rivers State.
}

\begin{abstract}
Solar energy is rapidly becoming an alternative means of electricity source. Fossil fuels are seriously depleting, thus the need for alternative energy source is a necessity. To make effective use of solar energy, its efficiency must be maximized. A feasible approach to maximizing the power output of solar array is by sun tracking. This paper therefore presents the design and construction of a solar tracking system that position the solar PV panel in proper orientation with the sun so as to always receive direct radiation. The prototype is designed around a programmed microcontroller which controls the system by communicating with the sensors and motor driver based on the movement of the sun.
\end{abstract}

\section{Introduction}

Over the years, researches and development of solar energy is rapidly gaining importance and attention especially in tropical areas of the globe. It is recognized as a bold step towards exploiting the providence of natural resources for the benefit of mankind and is continually harnessed as much as could be made possible by technological discoveries. Before now, non-renewable energy source such as fossil fuel had been the major means of generating electricity. The high dependence on it has resulted in consequential implications like fuel price fluctuation environmental hazard and global warming. Again studies suggest that the increasing rate at which fossil fuels are consumed might lead to their depletion by the end of this century [Narder B. and Paudian V., 2010]. Hence, there is great need for other means of electricity generation as an alternative. Renewable energy systems are presently becoming very popular. They are energy source gotten from natural resources such as wind, sunlight, water and thermal heat which can be renewed after use. Solar energy is one gotten from sunlight and is called photovoltaic system. Photovoltaic energy is the process of converting the sunlight directly to electricity, using solar cells [Antonio L. and Steven H., 2005]. It is clean, non polluting, sustainable resource that requires easy installation and little maintenance. Most solar panels are statically aligned, that is they are placed at a fixed position towards the sky. As the sun moves across the sky throughout the day, the angle of incendence of the sun rays to the panel keeps on changing thereby resulting to low power output from the solar cells [Rick J. and Chaiko Y., 2008]. Maximum energy is collected by the solar panel when the orientation is such that the sun rays fall directly on it. This means that the sunlight's angle of incidence has to be constantly perpendicular to the solar panel. Thus, a system which can continuously track the sun's radiation as it changes position in its motion during the day is the interest of this project.

The initial deployment of solar energy is very costly. More capacity electricity generation requires more solar panels (solar cells) which are rather expensive. Apart from cost, the conversion efficiency is low. Hence, there is need to improve the efficiency of solar system.

The aim and objective of this project is to design a solar tracker system that can continuously track sunlight to optimize energy produced from photovoltaic cells for maximum power generation.

The scope and limitation of this work involves the processes in successful development of an automatic solar tracking system which include researches and study of solar energy concepts as well as selection of appropriate components to achieve the design. The approach employed in the design mechanism of the system entails (i) Selection of components that constitutes the system design.(ii)Development and simulation of the circuit design.(iii)Assembly of components considering design parameters.(iv) Integration of the parts to develop the whole system.(v)Testing to ascertain overall functionality. This work incorporates latest technology and inexpensive electronic components to achieve maximum energy absorption, thereby making the system efficient and cost effective.

\section{Methodology}

Design concept: The design of solar tracking system originates from the need to improve the performance of the solar collector. A solar panel receives the morning and evening sunlight at an acute angle, thus reducing the total amount of electricity generated each day. The most attainable method of improving the performance of a solar power collector is to increase the mean intensity of radiation received from the source. This is achieved by tracking the sun. 
Fixed and tracking collector: In an ideal situation where atmospheric influence is negligible, the theoretical calculation of the energy surplus is carried out below. Assuming, the maximum radiation intensity, $\mathrm{I}=1100 \mathrm{w} / \mathrm{m}^{2}$ is falling on the area perpendicular oriented to the direction of radiation and the day length, $t=12$ hours $(43,200$ seconds).

For fixed solar collector,

The projection of the sun bean on the PV cell is given by

$$
S=\mathrm{S}_{\mathrm{o}} \cos \theta
$$

Where, $S_{0}$ is the collector area $\left(S_{o}=0.15 \mathrm{~m}^{2}\right)$

$\theta$ is the angle changing in the interval $(\pi / 2-\pi / 2)$ during the day.

The angular velocity of the sun moving across the sky,

$$
\omega=727 \times 10^{-7} \mathrm{rads} / \mathrm{sec}
$$

The differential of the falling energy,

$\mathrm{dE}=\mathrm{ISDt}$

$\mathrm{E}=\int_{-\pi / 2}^{\pi / 2} I s_{o} \cos w t d t$

$\left[I S_{o}\left[\frac{\sin w t}{w}\right] \pi / 2\right.$

$E=2 I S_{o}=\frac{2 \times 1100 \times 0.15}{727 \times 10^{-7}}=4.54 \times 10^{6}$ watt.S

For tracking collector,

$$
\begin{aligned}
& \mathrm{E}=\mathrm{IS}_{\mathrm{o}} \mathrm{t}, \quad \text { since } \theta=0^{\circ} \\
& \mathrm{E}=1100 \times 0.15 \times 43,200 \\
& \mathrm{E}=7.13 \times 10^{6} \text { Watt. } \mathrm{S}
\end{aligned}
$$

Therefore, comparison between the results shows that about $57 \%$ energy surplus increase is achieved with the tracking system.

System design: In the design for the automatic solar tracking system, a modular approach was used to break the project into separate tasks. Considering the project as a whole, it has a fixed vertical axis and a motor controlled horizontal axis. The signal from the light sensor is used to determine the direction of movement to align the array with the sun. a motor circuit is used to perform this movement based on the signal received from the controller.

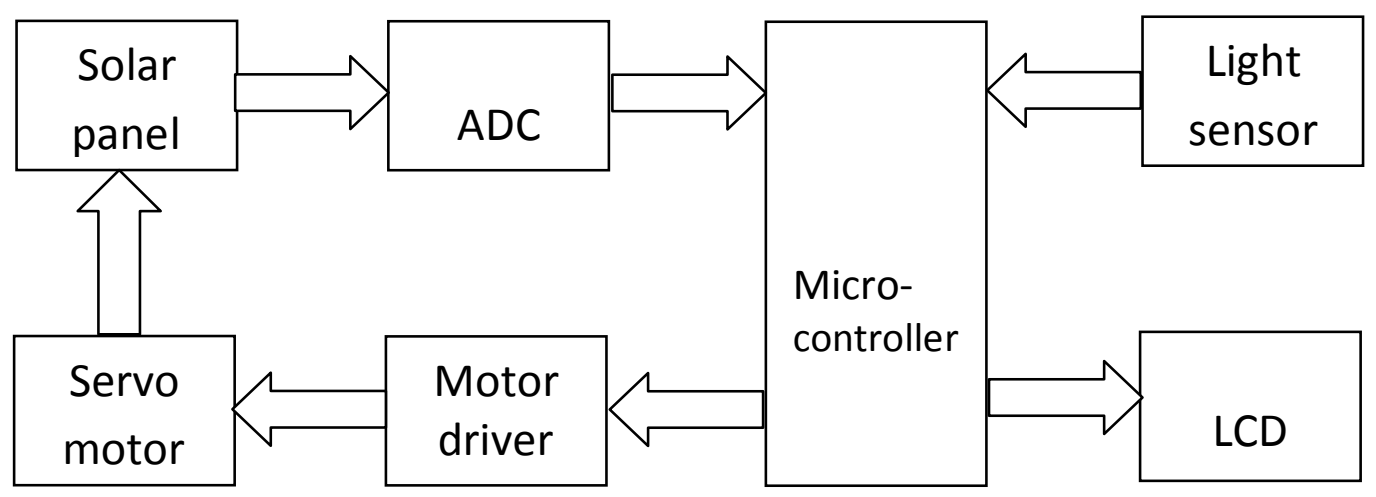

Figure 1.0: Block diagram of the solar tracking system

Microcontroller :The AT89S52 microcontroller serves as the brain of the project. It processes all the input signals supplied to the input pins and responds accordingly by giving control signals to the output pins. The input and output ports are configured in the program to specify their functions. It has 40 pins for the various configurations, special function pins inclusive. 


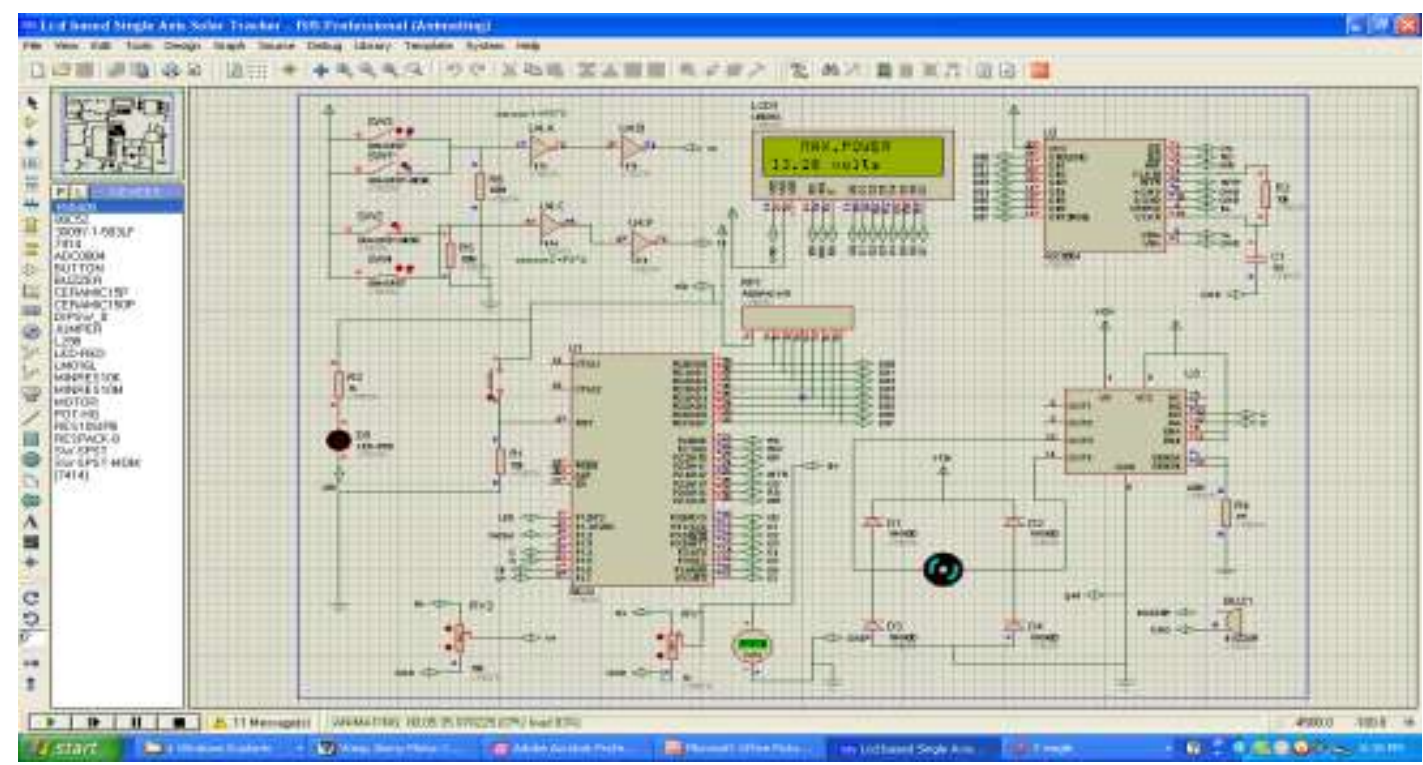

Figure 2.0: Circuit simulation of the solar tracking system.

The simulation circuit was designed using proteus professional software version 6.0. The components were picked from the library and connected appropriately as represented in figure 2.0. The switches represent the sensor with outputs connected to pins 7 and 8 of the microcontroller. The outputs from pins 5 and 6 are connected to input port, pins 10 and 12 of motor driver which controls the direction of motor movement through the output ports, pin 13 and pin14.The compiled program was transferred to the microcontroller after the design completion by right clicking and selecting the program file. Closing and opening the switches cause the motor to change direction while increasing and decreasing the voltage assumed from the panel give different values of power and voltage on the LCD.

\section{The Flow Chart}

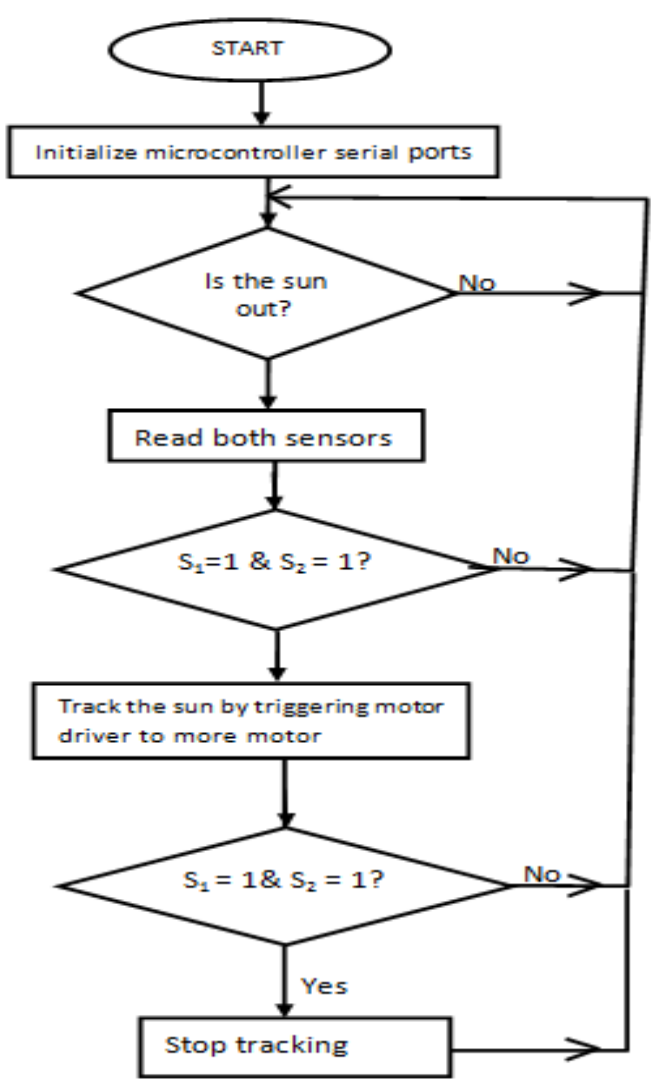




\section{System operation}

The operation of the solar tracking system is completely microcontroller based. This makes the operation simple because of the fact that microcontroller understands only two digits, 1 and 0 . The signals from the two sensor pairs $\left(s_{1}\right.$ and $\left.s_{2}\right)$ are always compared to detect any change in the value. Once the microcontroller detects 0 and 1 at its input ports (pin7and pin8), it sends signal to the motor driver through pin5 and pin6 to move the motor forward and equally send signal to stop the motor when the inputs are 1 and 1 . Table 3.2 illustrates the operation of the microcontroller with respect to the input signal from the sensors.

Table 1.0: Microcontroller controls conditions

\begin{tabular}{|l|l|l|}
\hline $\mathrm{S}_{1}$ & $\mathrm{~S}_{2}$ & Direction of motor \\
\hline 0 & 0 & Rest( Return of East) \\
\hline 1 & 0 & Anticlockwise \\
\hline 0 & 1 & Clockwise (East $>>$ west) \\
\hline 1 & 1 & Stop \\
\hline
\end{tabular}

The system is a single-axis solar tracker in order words, it is programmed to operate in unidirectional mode. Hence, it starts operating only when sensor 1 is 0 and sensor 2 is 1 . It was equally programmed to read the generated voltage from the panel through the ADC and compute power for display on the LCD.

\section{Data collection}

The value from PV panel in fixed mode and in tracking mode were measured and obtained at different hours of the day. This experiment was carried out on $10^{\text {th }}$ December, 2012 between 9am and $3 \mathrm{pm}$ at 1 hour intervals. The readings are as shown below.

Table 2.0Solar Output of PV Panel in Fixed Mode

\begin{tabular}{|c|c|c|c|}
\hline Time of the day & Voltage $(\mathbf{V})$ & Current $(\mathbf{A})$ & Power $(\mathbf{W})$ \\
\hline 9.00 & 13.87 & 0.88 & 12.21 \\
\hline 10.00 & 15.29 & 0.97 & 14.83 \\
\hline 11.00 & 15.09 & 0.95 & 14.34 \\
\hline 12.00 & 16.17 & 1.07 & 16.33 \\
\hline 13.00 & 18.08 & 1.17 & 21.15 \\
\hline 14.00 & 16.25 & 1.06 & 17.23 \\
\hline 15.00 & 15.88 & 0.99 & 15.72 \\
\hline
\end{tabular}

Table 3.0:Solar Output of PV Panel in Tracking Mode

\begin{tabular}{|c|c|c|c|}
\hline Time of the day & Voltage $(\mathbf{V})$ & Current $(\mathbf{A})$ & Power $(\mathbf{W})$ \\
\hline 9.00 & 16.04 & 0.95 & 15.24 \\
\hline 10.00 & 16.48 & 1.02 & 16.81 \\
\hline 11.00 & 16.40 & 0.98 & 16.07 \\
\hline 12.00 & 16.75 & 1.09 & 18.26 \\
\hline 13.00 & 18.09 & 1.17 & 21.16 \\
\hline 14.00 & 17.30 & 1.13 & 19.55 \\
\hline 15.00 & 16.83 & 1.11 & 18.68 \\
\hline
\end{tabular}

\section{Result}

The graphical representation of power output of both the fixed PV panel and the tracking PV panel against day time is shown in figure 3.0.

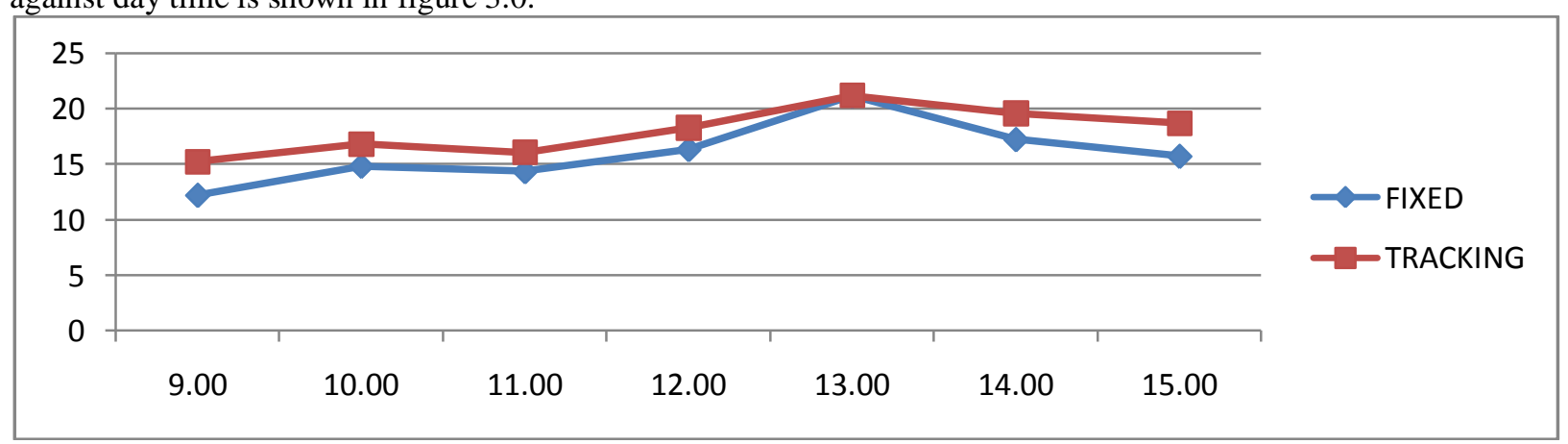


It illustrates improvement in efficiency gained with using solar tracking system.

From the graph, it can be seen that solar intensity increases with day time to maximum at $13 \mathrm{pm}$ and then starts decreasing. Some fluctuations notable in the graph were as a result of some cloudy sky and abnormal atmospheric condition. The percentage increase in solar power output gained is tabulated below.

Gain $(\%)=$ Power obtained by tracking mode - power obtained by fixed mode $\times 100$

$$
\text { Power obtained by fixed mode }
$$

Table 4.0: Percentage increase gained by tracking

\begin{tabular}{|c|c|c|}
\hline Power obtained by tracking mode & Power obtained by fixed mode & Percentage gain \\
\hline 15.24 & 12.21 & $24.82 \%$ \\
\hline 16.81 & 14.83 & $13.35 \%$ \\
\hline 16.07 & 14.34 & $12.06 \%$ \\
\hline 18.26 & 16.33 & $11.82 \%$ \\
\hline 21.16 & 21.15 & $0 \%$ \\
\hline 19.55 & 17.23 & $13.46 \%$ \\
\hline 18.68 & 15.72 & $18.83 \%$ \\
\hline
\end{tabular}

The table shows the percentage power increase that is obtained from tracking the sun with respect to that obtained without tracking. It is seen that at a point the power output of both the solar panel with and without tracking are the same. This is as a result of both panels facing the sun at the same time.

\section{Conclusion}

In view of this project report, it has been established that solar tracking system is an efficient and feasible means of obtaining optimal solar energy from the sun. By constantly aligning the photovoltanic panel with the sun, it directly receives sunlight falling on its surface thereby generating more electricity. Different techniques have been adopted in the design of this system but the method implemented in this project is simple, easy to maintain and requires no technical attention for its operation. The software developed for this work can be used outside the mechanical part, thus it is flexible for future modification. The solar module with tracking system as demonstrated in the analysis achieves about $24 \%$ efficiency improvement over the static solar module. Hence implementation of this technique in building solar systems will greatly improve utility satisfaction.

\section{References}

[1] Antonio L. and Steven H. (2005) "Handbook of Photovoltaic Science and Engineering", Wiley.

[2] Asmarashid P., Ammar H. and Handy M. (2011) "A Design of Single Axis Sun Tracking System", The 5 ${ }^{\text {th }}$ International Power Engineering and Optimization Conference, Malaysia, PP 107-110.

[3] Gagari D. and Arijit R. (2012) "Use of Solar Tracking System for Extracting Solar Energy", International Journal of Computer and Electrical Engineering, Vol.4.

[4] Lee C., Chou P., Chiang C. and Lin C. (2009) "Sun Tracking Systems: A Review", Sensors.

[5] Mohammed S., Mizanuel S., Rafe S. and Taufik S. (2011) "Solar Tracking System" National Conference on Electronic Technologies.

[6] Nader B. and Pandian V. (2010) "Simplified Solar Tracking Prototype", Global Journal on Technology and Optimization, Vol.1.

[7] Norbert C., Shi-Wei Z., Wai-Chuen G., Zhen-Gang S. and San-Chin K. (2008) "A solar tracking system design based on linear switched reluctance motor", Control Theory Applications, Vol.25.

[8] Plesz B., Sagi P. and Timar-Howath V. (2009) "Enhancement of Solar Panels" Power Generation by the Usage of Solar Tracking", Proceedings of ECOpole, Vol.3.

[9] Rick J. and Chaiko Y. (2008) "Solar Tracking System: More Efficient Use of Solar Panels", World Academy of Science.

[10] Theraja B. L. and Theraja A. K. (2009): A Textbook of Electrical Technology, 23rd Edition, S. Chand and Company Ltd., New Delhi. 